\title{
TOWARDS THE SUSTAINABLE CITY: A MODEL TO TRANSFORM THE INFORMAL INTO FORMAL
}

\author{
MIGUEL AMADO', INÊS RAMALHETE ${ }^{1,3}$, JOÃO C. FREITAS ${ }^{1,3}$, \\ ANTÓNIO AMADO ${ }^{2,3} \&$ ANA A. SILVA ${ }^{1,3}$ \\ ${ }^{1}$ CERIS Civil Engineering Research and Innovation for Sustainability, Portugal \\ ${ }^{2}$ CIAUD Centro de Investigação em Arquitectura, Urbanismo e Design, FAUL, Portugal \\ ${ }^{3}$ GEOTPU Gabinete de Estudos de Ordenamento do Território e Planeamento Urbano, Portugal
}

\begin{abstract}
Urban regeneration has been viewed as a path to a more sustainable city. In contrast with developed countries, where urban regeneration is seen as a renewal and adjustment to new trends, in developing countries it presents an opportunity to start from scratch. Aside from the pressing social-economic issues, several authors identify critical aspects in these informal settlements, these including: they are usually the only viable solution to transform the lives of the poorest in a meaningful and cost-effective way; and improvised solutions are within context and can use local resources and thus promote a more sustainable outcome. Thus, cities in developing countries can become a paradigm for urban development. This paper develops and discusses research on urban regeneration for developing countries based on the transformation of the informal into formal, within the framework of the sustainable city. A model to enable this transformation is presented. This model is designed at several scales, from policy to the actual physical transformation of the urban environment, creating a sequential process from concept to the implementation. The methodology combines a theoretical and empirical approach through the analysis of case studies and practical implementation. Public and private sector roles and actions are clearly defined and their physical results presented. Resulting urban options and the principles within the framework of the sustainable city as an inclusive "metabolism" based on social-economic and environment factors are discussed. The model is currently being implemented in the Oé-Cusse Region, in East-Timor, through a neighbourhood scale plan.
\end{abstract}

Keywords: developing countries, informal settlements, sustainable city, urban regeneration.

\section{INTRODUCTION}

Informal settlements accommodate a significant percentage of the urban population, mostly poor, in developing countries. In fact, according to the United Nations (UN), 880 million people lived in urban slums in 2014 [1]. Massive migrations are leading people to move outwards, beyond administrative boundaries, because there is no viable alternative. Cities remain magnets for those seeking greater opportunities and a better life resulting in urban sprawl and densification. While Eastern Asia and Oceania have the highest percentage of land consumption for urban purposes from 2000 to 2015, Latin America and the Caribbean and Southern and Central Asia regions have become more densely populated but did it through much higher densities [1] which can indicate the prevalence of overcrowded slums within these contexts. Financial efforts target, mostly, urban areas because urbanization is a major driver for development [2] and rural areas are left behind in national strategies and actions [3]. This situation enabled more internal migrations and thus a closed-loop in the urban-rural relationship [4].

Informal settlements are often rife with public health issues related to water and sanitation. [5], [6]. Moreover, food scarcity is also a problem that highlights two realities: according to some authors, "Urbanization processes are intertwined with nutritional transition because there is easier access to food of low nutritional quality at reduced prices" [7]. However, in rural areas, the lack of food due to the weak agricultural sector and vulnerability to natural disasters (e.g. heavy rains, floods, drought) result in food insecurity. 
In fact, informal settlements (both rural and urban) are usually exposed to natural disasters or man-made hazardous due to the lack of regulation and available land. According to the United Nations, the increasing of natural disasters resulted from climate changes, affected about 211 million annually from 2000 to 2013 [8]. Fast development in developing countries also has other consequences such as consumption patterns. As developing countries get industrialized, the use of natural resources and materials increases [9]. Lack of regulation and the need of an urgent solution for the growing cities aggravates this issue. Energy consumption is a consequence of such problem: on the one hand, massive industry, in such an early stage, and lack of regulation means huge amount of fossil energy consumption; on the other hand, low-quality buildings result in high consumption of energy to achieve liveable thermal comfort (ventilation, heating and cooling) [10]. In both cases, carbon emissions are high due to the industrialization process [11]. Moreover, sprawling informal settlements is also associated with increased emissions of carbon dioxide and hazardous pollution namely due to the weak mobility network that is a major concern for the low-income population as Turner [12] pointed out on the importance to combine the housing location and the journey to work.

However, some authors adopt a positive perspective on informal settlements. Turner [12] states that these settlements are a successful solution to the housing deficit because people have managed to create shelter and employment with few resources. Moreover, Steyn [13] claims that, putting aside the low-quality of the buildings, informal settlements might be the starting point to solve the problem through a self-building scheme and the available resources.

Although there has been an improvement in addressing all these problems, informal settlements are still growing (about $28 \%$ over the past 14 years), which hampers the sustainable development of these territories and societies [14]. This paper presents a model for a sustainable growing city to be applied in the city-capital of Pante Macassar, Oé-Cusse Ambeno Region in East-Timor. Apart from being an enclave, extreme biophysical features and past conflicts have hampered its development. This territory is marked by informality, lack of infrastructure and weak economic sector. All daily activities occur inside the housing plot which results in a society and economy based on agriculture and small businesses. However, these features will naturally change due to the development that is taking place in this region. Land tenure is based on customary law which makes it unclear [15]. Rather than solving the immediate problem of housing and development, the model shown in this paper aims to create an adaptive and resilient approach to future economic and social transformations related to "growth" in its various meanings.

\section{LITERATURE REVIEW}

Informal settlements are, in fact, the only viable solution for low-income population [16], [17] which is unable to acquire a house through formal channels. These settlements are growing so quickly that the scale of the problem and all the factors that they integrate become hard to solve as a whole and thus require an incremental and integrated approach [18], or rather, a gradual transformation of the informal into formal. Moreover, most of the regeneration strategies for these settlements are dependent on the economic factor which results many times in non-adequate solutions and, most important, neglects the integrated definition of the sustainable city that combines all factors regarding human activities and natural environment [19]. Progress had been made regarding this issue through different approaches and methods that discussed in this chapter.

Urban regeneration assumes different definitions and meanings. Inceruh and Nalbantoglu [20] consider urban regeneration as a renewal of the territory by proposing the three R's 
approach - "Reuse", "Recycle" and "Reduce". "Reuse" means the upgrading of buildings and flexibility of their use, supporting operations such as urban settlement upgrading already applied in several contexts. "Recycle" refers to the revitalization of a building or place with a new purpose of use while "Reduce" is a wider consequence of such actions, that is, lowering the use of resources. These authors perspective follows Roberts and Sykes' [21] approach on urban rehabilitation and renovation within a physical transformation of the territory. On the other hand, Couch [22] claims that urban regeneration moves beyond this physical transformation by adding the factors of the social and economic context. Alpopi and Manole [23] both agree with this approach by assuming that regeneration aims to solve not only the urban problems but, more importantly, to find a long-term upgrade of the social, economic, physical and environmental features of the intervention area, that is, what Donnison [24] pointed out as a "(...) coordinated way on problems and on the areas where those problems are concentrated". Development of informal settlements is linked to urban growth [25] and after years of debate and discussion [21], [26]-[28] on the most adequate solution, several regeneration approaches have been adopted and are discussed in the following chapter.

\subsection{Approaches towards urban regeneration in developing countries}

Public housing provided by the State has been a common approach since the 1950s and, as a principle, has been an essential element in affordable housing policy. However, this approach is outdated within the current social and economic context of developing countries due to the bureaucracy, resource constraints and political instability [29]. The first flaw of this approach is the fact that all the responsibility is in one entity - the public sector. This means that it is dependent of public resources and thus is heavily dependent of budgetary constraints [28]. This factor also conditions the location of the new settlements that are often built in peripheral areas where the land is cheaper, but are isolated from city dynamic and economic hubs [27], [29]. Although the land is, in fact, cheaper, infrastructure provision becomes an expensive process because of the large extension of pipes needed to connect the settlement to the existing urban network [30]. Developing countries, in most cases, have weak public transport infrastructure which means that cars are the principle mode of transport resulting in high traffic and large amount of carbon emissions [31]. Therefore, it was recognized that the state was unable to solve the housing deficit and the urban problems by itself which resulted in shifting regeneration approaches [12], [18], [32]. This approach had evolved in several ways. Nowadays, the state assumes the role of a facilitator instead of a provider, that is, it supports regeneration through indirect actions within policies, regulation and incentives that encourage the private investment propitiates community's self-determination [33].

At the operative level, site-and-service schemes had replaced, in a way, this approach. This combines an indirect public housing provision supported by private investment, where the state provides greenfield land with basic infrastructure and facilities, and the private sector develops urbanization [18] or, within a self-help context, people build their own houses [34]. Although the public financial effort is lower, land value and infrastructure expenditure is still a problem [30], [35] and thus the peripheral location of most of these settlements [36]. Moreover, in site-and-service schemes, once given access to the land, people could freely build their own houses [18]. Naturally, the lack of technical skills and assistance lead to similar situations to the existing informal settlements [34] which result in the creation of an assisted self-building process during three phases: project; construction; and later expansion and upgrade [37], [38].

At the policy level, several actions are highlighted. One of those actions is the expansion of supply of sites for new homes in existing residential areas through the identification of 
vacant public land. This action is supported by rezoning policies, namely inclusionary zoning, where a portion of affordable housing is mandatory as well as mixed uses to avoid large districts becoming dormitories that are only occupied off workhours [39]. This perspective follows the ideal of the Neighbourhood Unit and the provision of amenities [40] In fact, this concept is directly related with the sustainable city principles by considering social, economic and environmental features: mixed-uses enables local economic dynamic while proximity helps on social cohesion and community identity; environmental outcomes refer not only to the green structure that is inherently linked to the concept [41] but also due to the proximity factor that allows short distances between residential areas and the rest that can be done by foot.

Moreover, these zoning policies also support diversity in housing types to provide a wider housing supply [42]. This policy has huge impact on building regulation and thus in one of the major operative method on regeneration: review of building codes and standards [28]. One of the main features of developing countries is the settled informal economy that is, in most cases, occurs inside the housing plot [43]. A review of building codes show that an efficient way to adequate building standards to these contexts as long as public health and resident's safety is ensured. Economically and socially, this method has two paths such as: on the one hand, costs will be reduced due to the lower standards and thus avoid sudden rises in home prices and rents [28]; on the other hand, by keeping and enabling wealth generation within the housing plot, household income is ensured [43]. This method hampers development in an initial phase but the criteria of these standards should be carefully analysed to avoid creating housing stock similar to informal settlements with several consequences in terms of public health, thermal comfort and safety [44]-[46]. Zoning policies and the consequent review of building standards will support the upgrading approach informal settlements [2] [45]-[47]. This approach is a site-and-service applied in existing urban areas, avoiding the problems mentioned before. Although this approach is economically viable and socially accepted, land tenure is the major issue because, in most cases, it is unclear (most of the residents do not have land title or any other document) [48]. The other problem refers to the housing stock that does not have the needed equipment to connect to the public infrastructure.

This paper presents a model to transform the informal into formal that integrates several levels of approach, from policies to physical implementation thus combining governance, urban planning and architecture.

\section{METHODOLOGY}

This research combines both theoretical and empirical evidence, that is, a theoretical framework is established to ensure de adequacy of an empirical and holistic approach. The methodology has five stages. The first stage refers to context analysis, that is the creation of a database, based on empirical evidence and fieldwork through a survey method. The latter is based on Lynch and Hack's model [49] to assess social, economic and environmental features of the territory. The survey method was structured as follows: General Site Context; Physical Data, Site and Adjacent Land (integrating geology and soils, water, topography, climate, ecology, risks and man-made structures); Cultural Data, Site and Adjacent Land that includes the residents and using population features (numbers, composition, social structure and economic activities), site values and rights regarding land tenure and zoning, heritage and subjective data such as people's hopes, fears, wishes and preferences. Survey-method included a questionnaire to assess qualitative and quantitative from a sample (all the heads of the families living on the waterfront of the city -45 households) based on established survey methods [50]. This method also included a survey form for buildings that was 
complemented with direct observation. All this information was drawn from the community through their representatives. On the biophysical and statistical information, this was provided by the Regional Authority and validated during the fieldwork. Major projects (facilities, roads and infrastructure) was also provided by the Authority. All the information was collated in a GIS database. From this analysis, a SWOT analysis was created through the identification of the main needs and potential such as: key-points areas; areas to keep vacant and potential areas for development; ongoing changes and those likely to naturally occur; current and possible linkage areas where specific uses area desirable. This stage helps on the objectives to achieve and within the sort and long-term schedule.

The third stage refers to the theoretical approach to the identified needs and potential. This stage integrates the study of current approaches regarding urban regeneration in the developing world. A comparative case-study analysis is developed considering the advantages, the disadvantages and the flaws of these approaches regarding its context. Therefore, when designing the model, in the fourth stage, the following aspects are considered: (1) The territory has specific economic, social and environmental features - What are the main needs and potential? Can the latter be used to help solving the needs? (2) What kind of approaches are currently being applied in similar contexts? What were the failures and successes of such approaches? (3) The model's Design should consider its sustainability as a whole - affordability and economic viability; social adequacy; environmental adaption; and the durability of the project itself. The final stage refers to implementation and management of the model to be presented in further research. This last stage will take place one year after the implementation of the model to analyse the outcomes versus the identified needs. The survey-method was also applied in this phase to assess the building and infrastructure condition, similar to the method used by Syukrizal et al. [38] as well as social adequacy. According to the results, the model might be upgraded in phase 4 within an ongoing and incremental process.

\section{SUSTAINABLE CITY: A MODEL TO TRANSFORM THE INFORMAL}

The developed model is implemented as part of a broader, incremental strategy where as more and more people gain access to both affordable housing and critical utilities such as water and power so does entrepreneurship expand jobs and opportunities begin to concentrate. In turn this concentration will elevate the need for other "urban" services such as public spaces to cater to the growing population.

\subsection{Understanding the context}

Pante Macassar is characterized by informality, a weak infrastructure network, precarious housing and low income. On land tenure, the process is based on customary law and the absence of planning regulation resulted in housing located in risk or vulnerable areas. Lack of infrastructure aggravates this situation. Although $100 \%$ of the city is covered by the power grid, most houses do not have the equipment to connect to it and thus diesel generators and wood are the main power source. The same applies to the water network which means people are still using wells to access drinking water. The worst case is the sewage system that does not exist at all and thus most people use private latrines. Lack of infrastructure results in several public health problems: Data from 2015 shows that the main diseases were respiratory infection due to dust from non-paved roads (incidence of 337 per year) and diarrhoea (incidence of 80 per year but during the rainy season this value increases) due the absence of sewage treatment. Malnutrition is also a public health issue, namely due to the absence of power and to the consequential ability to preserve food: within the region, there 
is a prevalence of $12 \%$ and $15 \%$ of severe and moderate malnutrition, respectively, in Pante Macassar is about $16 \%$ and $10 \%$. On the building stock, housing is very precarious due to the bad quality of materials and building systems: mixed use of natural materials (palm tree leaves, straw and wood) with composite ones (cement blocks and zinc). While the first are efficient regarding the climatic context, their durability cannot be ensured, and the second compromise thermal comfort. Regarding the latter, traditional building layout hardly helps on ventilation, lighting and cooling. The housing stock, where a household with several families live, is mainly characterized by a large plot that has the several functions separated such as the living room/bedroom, kitchen, latrine and storage. $62 \%$ of the households have built their own houses while the remainder paid or asked other people to do it. Usually, a small area for subsistence agriculture can be seen. On the social-economic assessment, $11 \%$ of the surveyed households have a small business in the housing plot. Source of income comes, mostly, from agriculture and/or crafts (weaving, carpentry and pottery) all within an informal economy framework. This represents $31 \%$ of the surveyed population of the sample.

Notwithstanding these features, some potential can be identified and thus leveraged. The self-determination of the population in building their own houses within a context of lack of material and financial resources. Multifunctionality of the housing plots is another major potential such as orchards, workshops and small businesses, that is, existing residential areas naturally combine mixed uses and thus enables inclusionary zoning to support the efficiency of the neighbourhood unit.

\subsection{Interpreting current approaches and creating the research questions}

Some constraints regarding the current approaches on regeneration can be pointed out as mentioned in section 2 of this paper. Therefore, the following constraints have been identified led to some underlying research questions: (1) The cost of land compromises the effectiveness of new settlements and site-and-service schemes, that is, peripheral areas result in high expenditures on infrastructure. - What is the potential to adopt an incremental process for infrastructure that considers a first phase of small-scale infrastructure that can be later upgraded within the public network? (2) Peripheral settlements result in social exclusion and economic stagnation because they are located far away from economic hubs - Can an urban model create its own economic cycle and thus ensure its autonomy? (3) Land tenure is always unclear in such contexts - Can an urban model integrate tools for land regulation by considering a combination between policy/governance tools and physical tools for this purpose? (4) In some cases, infrastructure does exist but the building stock does not have the required equipment - Can an urban model provide a physical element that ensure this equipment and thus the connection to infrastructure network? (5) Adjustment of building codes is an important measure to cost reduction and functional adequacy - Can an urban model provide housing not only for shelter but also for other compatible functions to propitiate self-development of the dwellers? (6) Food insecurity is a common problem in informal settlements because people cannot preserve food and low purchase power hampers the acquisition of nutritive food - Can an urban model ensure food security?

\subsection{Transforming the informal into formal}

The model envisages the transformation of the informal into formal. For this purpose, an inclusive approach is required, that is, an approach that considers several levels, from policies to the house itself: (1) Policy; (2) Governance; (3) Territorial Management; (4) Infrastructure; (5) Technical Wall; (6) Incremental House. At the policy level, a public partnership is settled according to the Amado et al. model [18]. The public sector defines the intervention area 
regarding territorial aspects such as: proximity to the existing urban area/settlement and all its services; natural risks (floods); topography; winds and solar radiation. This will ensure a sustainable location for the urbanization: this new area will make use of the existing services but will also tackle needs; natural risks (flood areas) will be assets for food production and thus providing a new source of nutritious food as well as a formal source of income (profitable area); topography, winds and solar radiation will help on bioclimatic solutions both at the urban and building scale. The next step refers to inclusionary zoning based on mixed and complementary uses that will define the number of consumers and thus the revenues. Inclusionary zoning must consider density parameters. Both factors will contribute for the sustainability of the new urban area through the following outcomes: mixed uses to generate local economy and avoid long journeys between workplace/school and home (maximum distance of $800 \mathrm{~m}$ ); these mixed uses are based on the existing ones, that is, local social and economic features are boosted and thus the adequacy of the intervention increases; densification allows less expenditures on infrastructure and less time and energy consumption on journeys between workplace/school and home (net dwelling density of 48 dwellings per hectare). After land valorisation by the public sector, private sector provides housing, services and commerce (the latter will complement the small vendors within the housing plots). Moreover, inclusionary zoning defined by the State also establishes that a percentage of private investment should aim affordable housing within a rent-to-buy scheme for those that can afford it. In the other hand, the public sector should provide social houses for those that cannot. With this shared effort, the state will be able to channel its investment towards other critical areas. This action will have, as major outcome, social inclusion as far as social mix is mandatory and thus gentrification and social exclusion, that could be seen in site-and-service schemes, is avoided.

The second action refers to plot division, local roads and infrastructure network based on the inclusionary zoning and densities previously considered. It is important to point out the assessment of land tenure. Therefore, plots will have varying sizes and functions and mixed uses are encouraged, whose the only criteria is that these functions cannot compromise public health and safety. This premise will not only leverage existing economic activities but also create new ones which will transform, gradually, the informal into formal. At an early stage, and considering that the population have low-income or no income at all, services exchange is encouraged to propitiate entrepreneurship and local economy (potters will provide their service in exchange for agricultural goods). The design of the infrastructure network is a major action within the process. This network includes the provision of an infrastructure core inside each plot - Technical Wall (Fig. 1) - that will ensure not only access to basic infrastructure (water, sewage and energy) but also a structural element within the building process of the house based on assisted self-help. On the infrastructure, density and thus consumers are the main criteria: In some examples, small settlements do not justify huge investments in infrastructure, and community-scale infrastructure becomes a viable option (e.g. bio sand filter, wetlands and biogas settler). These might be gradually upgraded to centralized systems in accordance with the settlement's development and growth. After acquiring a plot with the Technical Wall, people are free to build their own houses according to the predefined guidelines and parameters. This will ensure the quality of the building system and a healthy home thought bioclimatic solutions (solar radiation, ventilation, natural lighting and cooling/heating). In terms of layout, the Technical Wall is the core of the house: it has all the water, sewage and energy equipment (pipes, cables, meters and switchboards) and corresponds to the kitchen and bathroom wall. This wall can be connected to communityscale infrastructure such as composting toilets, bio sand filters, wetlands and biogas settler and later connected to the public network. 


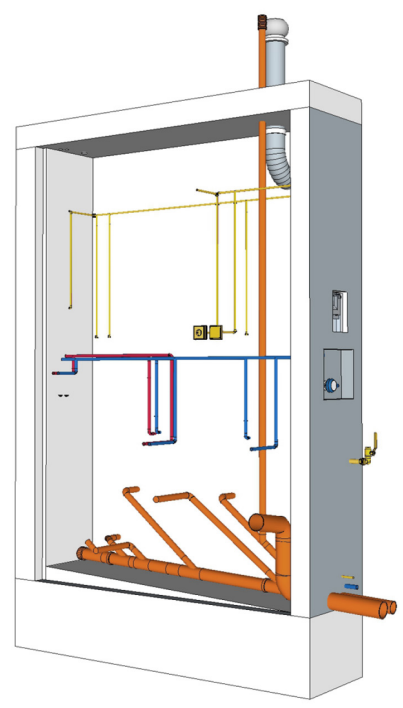

Figure 1: Technical wall.

\section{CASE STUDY}

Fig. 2 shows the model application in Pante Macassar in the Oé-Cusse Region, East-Timor. This is a neighbourhood of 113 families (around 530 people according to an average of 5 members per household), of which 7 families are already resident in the location. The plan combines varying housing plot types. The variation is related to the available area for complementary uses such as agriculture, small businesses and workshops. The plan also integrates the necessary components to establish a functioning and sustainable neighbourhood unit such as facilities/public space, open space and an agricultural area to support the neighbourhood. Although the primary focus was the self-sustaining aspect for the neighbourhood, the wider city context was also taken into account. A plan cannot be designed in a vacuum and therefore the balanced between different activities, open space and so on, had to be married to the existing citywide needs and opportunities.

As we are dealing with an environmentally vulnerable area, affected by floods and crossed by intermittent water courses, zoning design considered the adequate easement for flood protection. Therefore, the plots located in the eastern part of the new area have large courtyards to protect against possible risks. Moreover, the plan considered agricultural areas to be used by the community adjacent to the water course $(13,000 \mathrm{sqm})$. This equates to roughly around $120 \mathrm{sqm}$ per family. Although it is not expected that all families use this area, it is important as a complement for food security for some less advantaged families. It is also critical to note that most native residents, that are expected to populate the new homes, are mostly self-employed in some kind of agricultural activity. This plan also contemplates 7 larger plots for commercial activity. Today, most commercial activity in Pante Macassar occurs in a kind of home-made small shops. To increase economic activity and plan for future development, these plots would have a building with the necessary infrastructure to support all types of commercial activity both in the present modes (informal) to more regulated forms of commerce (formal). 


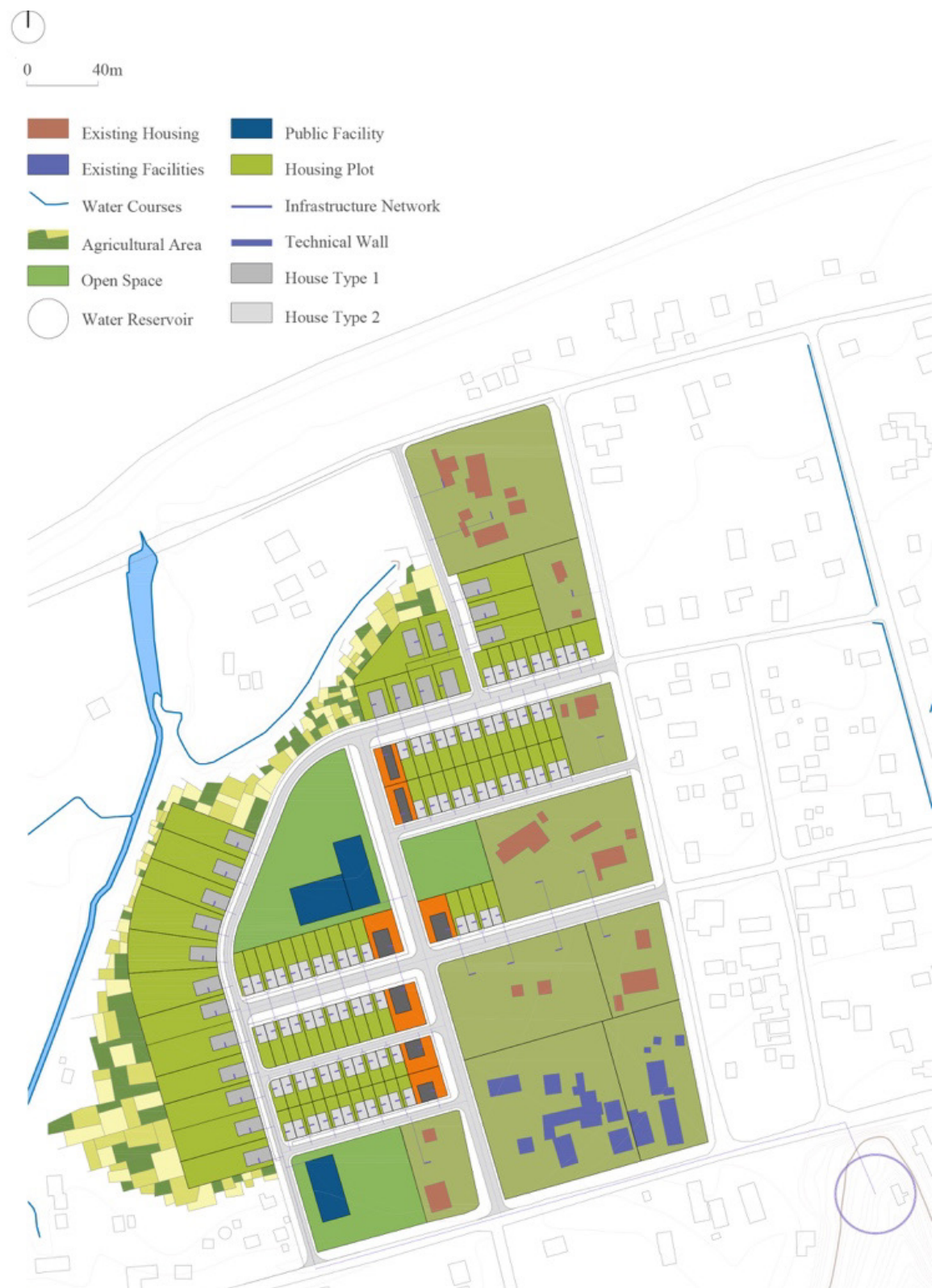

Figure 2: Model application in Pante Macassar, Oé-Cusse Region, East-Timor.

Regarding the basic infrastructure, and considering the local context, several options were analysed. The adopted solution takes into account the fact that the surrounding urban areas has a planned wetland system that can service this area and the incoming population needs (an area with about 8000 sqm for 1000 inhabitants). Each Technical Wall is connected to the grid that will itself discharge the sewage into the wetland treatment system. This grid can be 
later connected to a future public sewage network. With regards to the water system, a 250 CUM reservoir (bolted steel tank) has been proposed (considering a consumption per capita of 120L/day and an average of 5 members per household). As in the sewage system, the Technical Wall connects each house to the water supply network, that can be later upgraded into a centralized system, and can also quantify individual consumption (as each Technical Wall comes with pre-installed metering capabilities), which will, in the future, allow the distribution of costs according to the consumer-pays principle. Regarding the power network, the city is already covered, however, the existing housing stock does not have the equipment to connect to it. The Technical Wall will not only ensure this connection but also quantify individual power consumption though an energy meter, similar to the water system.

The urban design incorporated several aspects to improve quality of life maintenance costs as well as other advantages. A large majority of homes are oriented north-south to take advantage of the small, yet important, breeze emanating from the sea. This provides cooling and ventilation to outdoors and indoors spaces. Streets are lined with medium to large trees with wide canopies to provide shading to homes (lowering cooling costs) as well as pedestrians. It is worth noting that this plan achieves a very low footprint. Overall, around $20 \%$ or less of total plot areas are occupied by impermeable surfaces. This generates advantages in the functioning of the water cycle through increased infiltration of rain water.

\section{CONCLUSIONS}

In this paper an integrated planning process was designed and implemented in a remote region of East-Timor. Even though the plan was designed for the main city of the region Pante Macassar, the fact is that the existing homes and structures are either unsanitary or in disrepair. Regarding infrastructure these are non-existent. This situation led to the choosing of a type of site-and-service approach that is based on a single-element - the technical wall.

This approach brings several positive aspects such as the ability to use both local resources and manpower/workers, with the necessary training and logistical preparation. The Increasing of overall density and therefore justify some necessary facilities through a larger user base. Minimize costs by focusing on the technical wall to provide all necessary infrastructures. Adding flexibility to a planned community, which is always a challenge, through a participated and self-driven process of construction around the infrastructure core. Preparing future governance by integrating metering solutions in the product itself and thus facilitating control and costing analysis (since most of the utilities, when existing, are now free but will transition into paid in the near future). Furthermore, to achieve a sustainable outcome the plan integrated several strategies and solutions. In the environmental dimension the plan envisages several areas for risk mitigation through appropriate land use and occupation, mostly agriculture and grasslands. In economic aspect, the plan implemented a very flexible mixed use zoning approach (to enable "in-house" workshops and small stores), with the "central" avenue destined for larger commercial activities. Socially, the neighbourhood unit approach, which took into account the wider area and sought to create the necessary social facilities within walking (around $800 \mathrm{~m}$ ) distance is critically important as most residents today don't have a vehicle for more distant travel. The governance aspect of the sustainable approach is focused around the concept of the technical-wall as a unit for analysis and metering as well as the need, which is a pre-requisite of any plan, to legitimize land ownership and building rights which, at the moment, does not exist in this region. This approach, designed strategically in a holistic and integrated manner but whose designed is then developed from the bottom (technical-wall) up (plan design), is well poised to improve the quality of life of Pante-Macassar's residents and is flexible and durable enough to endure the coming decades of expected social and economic changes in the region. 


\section{REFERENCES}

[1] United Nations, The Sustainable Development Goals Report 2016, 1st ed., United Nations Publications: New York, 2016.

[2] Satterthwaite, D., Outside the Large Cities: The Demographic Importance of Small Urban Centres and Large Villages in Africa, Asia and Latin America, International Institute for Environment and Development: London, 2006.

[3] Rodríguez-Pose, A. \& Hardy D., Addressing poverty and inequality in the rural economy from a global perspective. Appl. Geogr., 61, pp. 11-23, 2015.

[4] Christiaensen, L. \& Todo Y., Poverty reduction during the rural-urban transformation - the role of the missing middle. World Dev., 63, pp. 43-58, 2014.

[5] World Health Organization (WHO), UN-water global analysis and assessment of sanitation and drinking-water (GLAAS) 2014 report: investing in water and sanitation: increasing access, reducing inequalities, 1st ed., World Health Organization Press: Geneva, 2014.

[6] WWAP (United Nations World Water Assessment Programme), World Water Development Report 2015: Water for a Sustainable World, 1st ed., UNESCO: Paris, 2015.

[7] Craveiro, I., et al., Determinants, Health problems, and food insecurity in urban areas of the largest city in Cape Verde. Int. J. Environ. Res. Public. Health, 13(11), p. 1155, Nov. 2016.

[8] Henderson, J.V., Storeygard, A. \& Deichmann U., Has climate change driven urbanization in Africa?. J. Dev. Econ., 124, pp. 60-82, Jan. 2017.

[9] Thapa, G.B. \& Weber, K.E., Issues in natural resources management in developing countries. Nat. Resour. Forum, 18(2), pp. 115-123, May 1994.

[10] Amado, M.P., Reaes Pinto, A., Alcafache, A.M. \& Ramalhete, I., Construção Sustentável - Conceito e Prática, 1st ed., Caleidoscópio: Casal de Cambra, 2016.

[11] Geng, Y., Wei, Y.-M., Fischedick, M., Chiu, A., Chen, B. \& Yan, Y., Recent trend of industrial emissions in developing countries. Appl. Energy, 166, pp. 187-190, Mar. 2016.

[12] Turner, J., Uncontrolled Urban Settlement: Problems and Policies. Urbanization: Development Policies and Planning, International Social Development Review No. 1, United Nations: New York, 1968.

[13] Steyn, G., Sustainable African settlement: Profiling a vision, Tshwane University of Technology, Pretoria, South Africa, 2003.

[14] United Nations Human Settlements Programme (UN-Habitat), Urbanization and Development: Emerging Futures - World Cities Report 2016, 1st ed., United Nations Human Settlements Programme (UN-Habitat): Nairobi, 2016.

[15] Fitzpatrick, D., Land claims in East Timor: A preliminary assessment. SSRN Electron. J., 2012.

[16] Basu, A.R., Urban Squatter Housing in Third World, Mittal Publications, 1988.

[17] Huchzermeyer, M. \& Karam, A., Informal Settlements: A Perpetual Challenge? Juta and Company Ltd, 2006.

[18] Amado, M.P., Ramalhete, I., Amado, A.R. \& Freitas, J.C., Regeneration of informal areas: An integrated approach. Cities, 58, pp. 59-69, 2016.

[19] Ahvenniemi, H., Huovila, A., Pinto-Seppä, I. \& Airaksinen, M., What are the differences between sustainable and smart cities?. Cities, 60, pp. 234-245, Feb. 2017.

[20] Inceruh, C. \& Nalbantoglu, O., Rediscovering the principles of the Eco-City as spatial attributes in traditional housing settlement: The case of Urfa in Southeastern Anatolia. Int. J. Archit. Res. ArchNet-IJAR, 3(3), pp. 65-79, Jan. 2014. 
[21] Roberts, P. \& Sykes, H., Urban Regeneration: A Handbook, SAGE, 2000.

[22] Couch, C., Urban Renewal: Theory and Practice, Macmillan, 1990.

[23] Alpopi, C. \& Manole, C., Integrated urban regeneration - solution for cities revitalize. Procedia Econ. Finance, 6, pp. 178-185, 2013.

[24] Donnison, D.V., The Good City: A Study of Urban Development Policy in Britain, Ashgate Pub Co: London, 1980.

[25] Payne, G.K., Urban Housing in the Third World, Routledge Kegan \& Paul: London \& Boston, 1977.

[26] Abbott, J., A method-based planning framework for informal settlement upgrading. Habitat Int., 26(3), pp. 317-333, Sep. 2002.

[27] Keivani, R. \& Werna, E., Modes of housing provision in developing countries. Prog. Plan., 55(2), pp. 65-118, Feb. 2001.

[28] Wekesa, B.W., Steyn, G.S. \& Otieno, F.A.O. (Fred), A review of physical and socioeconomic characteristics and intervention approaches of informal settlements. Habitat Int., 35(2), pp. 238-245, Apr. 2011.

[29] Mukhija, V., The contradictions in enabling private developers of affordable housing: A cautionary case from Ahmedabad, India. Urban Stud., 41(11), pp. 2231-2244, Oct. 2004.

[30] Bredenoord, J. \& Lindert, P. van, Pro-poor housing policies: Rethinking the potential of assisted self-help housing. Habitat Int., 34(3), pp. 278-287, Jul. 2010.

[31] Ahmad, S. \& Puppim de Oliveira, J.A., Determinants of urban mobility in India: Lessons for promoting sustainable and inclusive urban transportation in developing countries. Transp. Policy, 50, pp. 106-114, Aug. 2016.

[32] Mehdipour, A. \& Nia, H.R., Industrialization and city change: The concept and historical evolution of urban regeneration. Int. J. Sci. Basic Appl. Res. IJSBAR, 12(1), pp. 176-181, Dec. 2013.

[33] Reeves, P., Affordable and Social Housing, Routledge, 2013.

[34] Greene, M. \& Rojas, E., Incremental construction: A strategy to facilitate access to housing. Environ. Urban., 20(1), pp. 89-108, Apr. 2008.

[35] Ogunshakin, L. \& Olayiwola, L., The collapse of official housing policy in Nigeria. Habitat Int., 16(1), pp. 41-53, 1992.

[36] Okpala, D.C., Housing production system and technologies in developing countries: A review of the experiences and possible future trends/prospects. Habitat Int., 16(3), pp. 9-32, 1992.

[37] Aravena, A. \& Iacobelli, A., Alejandro Aravena: Elemental: Incremental Housing and Participatory Design Manual, 2nd ed., Hatje Cantz: Ostfildern, 2016.

[38] Syukrizal, A., Wardah, H. \& Sauter, G., Reconstructing life after the Tsunami: The work of Uplink Banda Aceh in Indonesia. IIED, 2009.

[39] Schuetz, J. \& Meltzer, R., Inclusionary zoning to support affordable housing. International Encyclopedia of Housing and Home, Elsevier, pp. 32-36, 2012.

[40] Collison, P., Town planning and the neighbourhood unit concept. Public Adm., 32(4), pp. 463-469, Dec. 1954.

[41] Patricios, N.N., Urban design principles of the original neighbourhood concepts. Urban Morphol., 6(1), pp. 21-32, 2002.

[42] Center of Housing Policy, Homes for Working Families: Increasing the Availability of Affordable Homes - A Handbook of High-Impact state and Local Solutions, 1st ed., Center for Housing Policy: Washington, DC, 2006. 
[43] Werna, E., Shelter, employment and the informal city in the context of the present economic scene: Implications for participatory governance. Habitat Int., 25(2), pp. 209-227, Jun. 2001.

[44] Sengupta, U., The hindered self-help: Housing policies, politics and poverty in Kolkata, India. Habitat Int., 34(3), pp. 323-331, Jul. 2010.

[45] Tunas, D. \& Peresthu, A., The self-help housing in Indonesia: The only option for the poor?. Habitat Int., 34(3), pp. 315-322, Jul. 2010.

[46] Yap, K.S. \& Wandeler, K. de, Self-help housing in Bangkok. Habitat Int., 34(3), pp. 332-341, Jul. 2010.

[47] Wegelin, E., Informal settlements and their upgrading: building on the lessons of three decades of experience. Ministerial Conference on Informal Settlements in South Eastern Europe, Vienna, 2004.

[48] Asperen, P. van, Evaluation of Innovative Land Tools in Sub-Saharan Africa: Three Cases from a Peri-Urban Context, IOS Press, 2014.

[49] Lynch, K. \& Hack, G., Site Planning (text only), 3rd ed., MIT Press: London, 1984.

[50] Babbie, E.R., Survey Research Methods, Wadsworth Publishing Company, 1990. 